\title{
A radiografia simples de tórax
}

The simple chest radiography

Marcel Koenigkam Santos ${ }^{1}$

$\mathrm{R}^{\mathrm{a}}$ adiologia e Diagnóstico por Imagem é uma especialidade médica que envolve todos os aspectos dos exames de imagem de uso na medicina, que fornecem informações não somente sobre o diagnóstico de uma doença, mas também sobre a anatomia normal e suas variantes, função dos órgãos e sistemas, fisiopatologia, gravidade e prognóstico das doenças. Ela também agrega técnicas intervencionistas pouco invasivas para diagnóstico e tratamento, que incluem sistemas guiados por imagem ${ }^{1}$.

Os principais exames de imagem de competência da Radiologia são:

- $\quad$ Radiografia simples (RX) e contrastada

- $\quad$ Angiografia de subtração digital

- Ultrassonografia (US)

- $\quad$ Tomografia computadorizada (TC)

- $\quad$ Ressonância magnética (RM)

- Procedimentos intervencionistas guiados por imagem

A Radiologia é uma especialidade em constante avanço e atualização, o que torna difícil, mesmo para o especialista, manter-se sempre atualizado em relação a todos os métodos e doenças dos diversos sistemas. Os avanços são tantos que nos últimos anos a especialidade tem se aproximado cada vez mais de outras áreas médicas como a genética e biologia molecular, além de outros campos da ciência como a informática biomédica e bioengenharia, interagindo com ferramentas de inteligência artificial e criando novas tecnologias, como a Radiômica e Radiogenômica ${ }^{2}$. Para o aluno de graduação em medicina, que precisa aprender tudo o que faz parte das grandes áreas clínicas para sua formação como médico generalista, conhecer melhor a Radiologia torna-se um desafio maior ainda. Assim, é importante focar e aprender realmente o básico, aquilo que todo médico deve saber ${ }^{3}$. Desta maneira, podemos destacar os seguintes Objetivos Gerais a serem alcançados na graduação:

- Interpretar os exames de RX das condições mais comuns, como pneumonia, insuficiência cardíaca, oclusão intestinal e fraturas

- Conhecer os princípios de formação e aquisição das imagens das principais modalidades radiológicas

- $\quad$ Saber indicar os demais exames especializados, como US, TC e RM

- Conhecer, de maneira geral, as vantagens, desvantagens, contraindicações e possíveis efeitos colaterais dos exames de imagem e seus meios de contraste

Dentro da disciplina de Radiologia Torácica e Cardiovascular, estas diretrizes se aplicam principalmente ao exame de RX de tórax. O exame de RX na avaliação do tórax representa o método de

1. Docente responsável pela disciplina de Radiologia Torácica e Cardiovascular. Fundação de Apoio ao Ensino, Pesquisa e Assistência do Hospital das Clínicas da Faculdade de Medicina de Ribeirão Preto da Universidade de São Paulo (FAEPA), Ribeirão Preto (SP), Brasil.

座 Avenida Bandeirantes, 3900 - Campus Universitário. CEP: 14049-900. Ribeirão Preto SP, Brasil. marcelk46@fmrp.usp.br 
imagem mais antigo, mais barato, mais disponível e tecnologicamente mais simples, desta maneira representando, na maioria das situações, o primeiro exame radiológico a ser solicitado para avaliação das doenças torácicas ${ }^{4}$. O aparelho de RX está comumente disponível mesmo nas unidades básicas de atendimento de saúde, fora dos grandes centros urbanos, e possui ainda a vantagem de ser móvel, permitindo a realização de exames de pacientes acamados, no centro cirúrgico, centro de terapia intensiva ou nas salas de atendimento de urgência e trauma. Portanto, ressalta-se que TODO MÉDICO DEVE SABER INTERPRETAR AS ALTERAÇÕES MAIS COMUNS IDENTIFICADAS AO EXAME DE RX DE TÓRAX ${ }^{5}$. Além disto, conhecer alguns aspectos dos demais exames utilizados na avaliação por imagem das doenças torácicas também é importante, principalmente a TC de tórax, exame que normalmente complementa o RX.

Diante disto, dentro da disciplina de Radiologia Torácica e Cardiovascular, sugerem-se os seguintes Objetivos Específicos para o graduando em medicina, que também servem de roteiro de estudo:

- Conhecer os aspectos técnicos do exame de RX de tórax

- Reconhecer as incidências radiográficas

- Sistematizar a avaliação do RX de tórax

- Conhecer a anatomia radiográfica normal do tórax, em correlação com a anatomia e fisiologia

- Ter noções básicas de anatomia nos demais exames de imagem ("o que dá para ver")

- Conhecer e utilizar a semiologia e terminologia radiológica correta nos exames de RX e TC de tórax

- Reconhecer os sinais radiológicos mais característicos (acrescentam especificidade)

- Saber avaliar os aparatos médicos mais comumente identificados nos exames radiográficos do tórax

- Conhecer as principais indicações dos exames complementares ao RX de tórax e ter noções sobre os protocolos de TC de tórax (uso ou não do meio de contraste, necessidade de colaboração e apneia, princípios das aquisições)

- Interpretar condições comuns ao RX de tórax (diagnóstico sindrômico - padrões radiográficos) como: pneumonias, outros padrões infecciosos e suas complicações, insuficiência cardíaca, hiperinsuflação pulmonar (doenças obstrutivas), bronquiectasias, doenças intersticiais pulmonares fibrosantes e granulomatosas, nódulos e massas (benignas e malignas), lesões traumáticas, doenças pleurais (derrame, pneumotórax) e alterações mediastinais (alargamento)

- Saber correlacionar os padrões radiográficos das doenças com as alterações identificáveis nos demais exames de imagem, principalmente a TC

Assim, neste Suplemento Temático em Radiologia Torácica e Cardiovascular, focamos na avaliação do RX de tórax, incluindo a parte técnica, a anatomia radiográfica, as importantíssimas semiologia e terminologias radiológicas, os sinais radiográficos que acrescentam especificidade e a identificação dos principais aparatos médicos. Os textos estão organizados em forma de estudo dirigido, com exercícios ao final e as respostas disponíveis em texto suplementar.

\section{REFERÊNCIAS}

1. European Society of Radiology. European Training Curriculum for Radiology. Jun 2018. Disponível em http://www.myesr.org/ trainingcurriculum.

2. R. Gillies, P. Kinahan, and H. Hricak. Radiomics: Images Are More than Pictures, They Are Data. Radiology, vol. 278, no. 2, pp. 563-77, 2016.

3. European Society of Radiology. Curriculum for Undergraduate Radiological Education. Jun 2018. Disponível em http://www.myesr.org/trainingcurriculum. 
4. Freitas MB De, Yoshimura EM. De Diagnóstico Por Imagem E Da Freqüência De Exames Radiológicos No Estado De São Paulo. Radiol Bras. 2005;38(5):347-354. doi:10.1590/S0100-39842005000500008

5. Accreditation Council for Graduate Medical Education, Common Program Requirements, Effective July 1,2011 http://www.acgme.org/acwebsite/home/Common_Program_Requirements_07012011.pdf) 